\title{
GESTÃO DE PESSOAS: EXPERIÊNCIAS NO SETOR PÚBLICO
}

\section{PEOPLE MANAGEMENT: EXPERIENCES IN THE PUBLIC SECTOR \\ GESTIÓN DE PERSONAS: EXPERIENCIAS EN EL SECTOR PÚBLICO}

\section{Martha Marques Rahn}

Especialista em Gestão de pessoas e Pós-graduanda em Psicologia Positiva Aplicada

Sócia e Diretora de Partner Success na Tecnosenior

E-mail: martha.rahn@outlook.com

\section{Lilian Weber}

Doutora em Administração com Ênfase em gestão de pessoas pela Universidade Federal do Rio Grande do Sul (UFRGS)

E-mail: lilian@Iweber.com.br

Artigo recebido em 01/05/2019. Revisado por pares em 10/05/2019. Reformulado em 11/05/2019. Recomendado para publicação em 15/12/2019. Publicado em 23/12/2019. Avaliado pelo Sistema double blind review. 


\section{RESUMO}

O objetivo deste estudo é verificar e analisar as tendências da gestão de pessoas no setor público, para o qual foram realizadas entrevistas em cinco organizações públicas sediadas em Porto Alegre. Utilizando-se a análise de conteúdo, sistematizou-se as 'boas práticas' encontradas em oito categorias: acompanhamento, avaliação de desempenho, capacitação, cargos e salários, desenvolvimento de lideranças, estrutura do Recursos Humanos, programas e planejamento de pessoal, sendo capacitação a categoria mais citada. A revisão de literatura e o estudo de caso demonstraram que as peculiaridades do setor público não impedem sua modernização em relação à gestão estratégica de pessoas.

Palavras-Chave: Gestão de pessoas; Setor público; Boas práticas de gestão.

\section{ABSTRACT}

This study aims to verify and analyze people management trends in the public sector, for which interviews were carried out in five public organizations based in Porto Alegre. Using content analysis, the 'good practices' found have been systematized into eight categories: counseling, performance evaluation, qualification, careers and salaries, leadership development, Human Resources structure, programs, and personnel planning, qualification being the most quoted category. The literature review and the case study have shown that the public sector peculiarities do not prevent its modernization in relation to the strategic management of people.

Keywords: People management; Public sector; Good Practices of management.

\section{RESÚMEN}

El objetivo de este estudio es verificar y analizar las tendencias de gestión de personas en el sector público, para lo cual se realizaron entrevistas en cinco organizaciones públicas con sede en Porto Alegre. A través del análisis de contenido, se sistematizaron las 'buenas prácticas' encontradas en ocho categorías: acompañamiento, evaluación del desempeño, capacitación, cargos y salarios, desarrollo del liderazgo, estructura del Recursos Humanos, programas y planificación de personal, siendo que capacitación fue la categoría más citada. La revisión de la literatura y el estudio de caso demostraron que las peculiaridades del sector público no impiden su modernización en relación con la gestión estratégica de personas.

Palabras Clave: Gestión de personas; Sector público; Buenas prácticas de gestión. 


\section{INTRODUÇÃO}

O crescente acesso à informação transformou a relação entre a sociedade e as empresas, as quais, cada vez mais, são publicamente avaliadas por seus clientes. Esse contexto incentiva a mudança dos modelos de gestão e impacta, de maneira particular, as organizações públicas que, tradicionalmente, vêm se mantendo no mercado, independentemente da avaliação de seus usuários. Nesse processo, instituições públicas buscam caminhos singulares para alcançarem a eficiência e a eficácia, haja vista que a importação de modelos da esfera privada não se mostra como uma solução adequada.

As frentes de atuação da gestão são múltiplas, no entanto, o foco deste estudo recai nos processos e práticas que tangem à gestão de pessoas. Entende-se que, no momento em que procedimentos e tecnologias são compartilhados com alguma facilidade, o diferencial estratégico se encontra na ação dos profissionais. Desta forma, observa-se a transformação do departamento de recursos humanos (RH) em departamento de gestão de pessoas (GP), do qual se espera um posicionamento menos operacional e mais alinhado aos objetivos organizacionais (MATOSO et al., 2016).

Tornar a área de recursos humanos uma parceira estratégica do negócio - atuando no planejamento de pessoal, na capacitação, na avaliação de desempenho com base em competências, etc. - é um desafio tanto para empresas privadas quanto públicas (MATOSO et al., 2016; SILVA \& MELLO, 2011). Segundo Pinto e Silva (2015), a percepção geral da qualidade dos serviços de $\mathrm{RH}$ em organizações privadas é semelhante à do setor público. Porém, os modelos de gestão de pessoas utilizados nessas não podem ser diretamente reproduzidos neste, sendo fundamental considerar suas particularidades.

Como pano de fundo, o modelo burocrático de administração pública teve a intenção de direcionar para a impessoalidade, a hierarquia, a profissionalização e o formalismo, com o propósito de erradicar a corrupção e o nepotismo existentes no período patrimonialista. Por conseguinte, foi preciso implantar controles rígidos de processos e de ingresso à carreira (PINTO \& SILVA, 2015). Como medida de compensação disfuncional, a cultura de intolerância à incerteza gerou a criação excessiva de normativos, distanciando a administração pública dos resultados e da satisfação das necessidades sociais. Outra consequência desse modelo foi dificultar que o corpo funcional desenvolvesse seu potencial, uma vez que teve sua 
motivação e sua iniciativa reprimidas, o que o tornou pouco comprometido e emocionalmente desligado do trabalho (CARVALHO, 2014).

De acordo com Camões, Fonseca e Porto (2014), para viabilizar a modernização do serviço público, é essencial modernizar a gestão de pessoas, já que os servidores são os agentes detentores de recursos técnicos e comportamentais que compõem a capacidade necessária à organização para implementar sua missão. A partir dessa premissa, pretende-se investigar-se práticas de gestão de pessoas utilizadas pelos departamentos de $\mathrm{RH}$ de organizações públicas, buscando identificar e analisar as tendências deste setor que sejam indicativas de aproximação a um modelo mais estratégico.

Busca-se verificar quais das atividades de RH propostas por uma amostra de entes públicos sediados em Porto Alegre são consideradas 'boas práticas' e que tipos de ações de gestão de pessoas estão sendo nacionalmente valorizadas, considerando os critérios adotados pelo Concurso Inovação no Setor Público, da Escola Nacional de Administração Pública (ENAP). Considera-se de extrema relevância dar visibilidade aos exemplos de organizações públicas brasileiras que estão modernizando suas práticas de gestão de pessoas, ponderando avanços e dificuldades.

A próxima seção discorre sobre a gestão estratégica de pessoas e a seguinte apresenta aspectos da gestão de pessoas na área pública, mesclando teoria e prática com exemplos de outros estudos. Na sequência, expõem-se os procedimentos metodológicos desta pesquisa, bem como os resultados encontrados e sua análise. Encerrando o artigo, estão as conclusões e as referências utilizadas como fundamentação teórica.

\section{GESTÃO ESTRATÉGICA DE PESSOAS}

As organizações são sistemas sociais nos quais pessoas integradas a equipamentos diversos atuam em prol de um objetivo comum. No campo organizacional, o que gera diferencial competitivo, segundo Donida e Oliveira (2012, p. 187), é o conhecimento, ou o capital humano e intelectual, que é único em cada organização, já que "capital, equipamentos e instalações são passíveis de serem nivelados pelas concorrentes [...]". 
O reconhecimento das pessoas como um dos mais importantes recursos de competitividade data do início da década de 1980, induzindo uma transformação no setor de RH. O RH tradicional, ou departamento de pessoal, tinha um papel burocrático dentro da empresa e era visto apenas como um custo. Ao encarar o potencial dos empregados como oportunidades, passou a desempenhar um papel de parceiro estratégico, “[...] auditor de competências e cultura da empresa, mobilizador do comprometimento e empenhamento organizacional" (MOTA \& CORDEIRO, 2015, p. 94).

Para atuar como parceiro estratégico, o RH passa a assumir múltiplas funções, conforme analisam Matoso et al. (2016), tendo como base o modelo de Ulrich, tais como: gestor das estratégias de $\mathrm{RH}$; agente de transformação e mudança; defensor dos funcionários (gestão das contribuições); e especialista administrativo (departamento de pessoal). Esse modelo engloba desde o gerenciamento de processos até a gestão de pessoas, do curto ao longo prazo. Complementarmente, Noman (2012) afirma que, para que um projeto de gestão de pessoas seja bem-sucedido e duradouro, é fundamental fazer, completa e periodicamente, o mapeamento e a revisão de seus macro e microprocessos, demonstrando a interdependência e a ordem de prioridades.

Um importante recurso de gestão estratégica de pessoas é a gestão por competências (SILVA, PERRET \& PARDINI, 2015), que consiste em gerir a capacitação do corpo funcional desenvolvendo conhecimentos, habilidades e atitudes de forma conjunta. Isso permite o adequado desempenho das atividades e da carreira de cada empregado, contribuindo para o alcance dos resultados específicos, de modo a atingir os objetivos da empresa. Essa gestão deve ser efetuada cruzando o mapeamento de competências organizacionais e individuais imperativas à consecução da estratégia com o diagnóstico das competências existentes. Em outras palavras, é trabalhar as lacunas de competências existentes entre o que a organização é hoje e o que ela pretende se tornar (GARCIA, 2014; CAMARGO et al., 2016).

Um aspecto decisivo para o processo de consecução das metas organizacionais é o envolvimento dos trabalhadores. E, para que estes contribuam com os objetivos estratégicos, a empresa deve desenvolver ou influenciar seu comportamento (MOTA \& CORDEIRO, 2015), levando em consideração que a clareza de propósitos, a recompensa e o 
reconhecimento são fundamentais para alcançar o sucesso com as pessoas (CAMARGO et al., 2016). Cada empregado se entrega à organização com base em sua avaliação individual de custo/benefício, por isso, a organização deve conhecer e envolver seu colaborador no trabalho (SILVA, 2014), com atenção especial aos que são altamente qualificados, que trazem vantagens em um contexto de competitividade (MOTA \& CORDEIRO, 2015). Uma maneira de verificar as percepções compartilhadas pelo corpo funcional, em relação ao ambiente de trabalho, é analisar o clima organizacional, que reflete o estado de espírito predominante na organização em um determinado período (FIORENSE \& MARTINEZ, 2016).

Outra ferramenta de gestão de pessoas é a avaliação de desempenho, prática intensificada na década de 60. Apesar de ser uma atividade gerida e apoiada pela área de $\mathrm{RH}$, o avaliador e o avaliado são os maiores responsáveis pelo processo. A etapa principal não é a avaliação em si, mas todo o ciclo de gestão de desempenho: criação de um plano de trabalho claro e desafiador, com o estabelecimento de expectativas e prioridades; acompanhamento e orientação constantes, com feedback do desempenho e manutenção das expectativas; autoavaliação; e avaliação formal (ORSI \& SILVA, 2014; SIQUEIRA \& NASCIMENTO, 2016).

A avaliação de desempenho diretamente relacionada à remuneração torna a confiabilidade dos resultados e sua utilização para o desenvolvimento profissional questionáveis, potencializando as chances de erro. A justificativa dos gestores, em caso de tendência de superavaliações, é o receio de prejudicar a evolução salarial do empregado e gerar a falta de cooperação. Estudos mostram, inclusive, que as notas atribuídas costumam ser menores quando o desenvolvimento profissional é a única consequência da avaliação (ALMEIDA, SILVA \& GASPAR, 2014; SILVA, PERRET \& PARDINI, 2015).

A educação corporativa é, igualmente, um conceito estratégico de gestão de pessoas, já que ajuda a transformar informação em conhecimento, gerando não só enriquecimento intelectual como potencializando o desempenho. Sua meta é desenvolver e educar o corpo funcional, clientes, fornecedores e sociedade para o alinhamento das demandas organizacionais. Difere-se da formação externa à medida que educa para a cultura e realidade da empresa. Ou seja, o conhecimento é trabalhado de acordo com os valores da organização, alinhando competências individuais e organizacionais para gerar vantagem 
competitiva para ambos (DONIDA \& OLIVEIRA, 2012). Para Travi et al. (2016, p.9), "as organizações do futuro serão aquelas que descobrirem a melhor forma de envolver seu capital humano na cultura da educação [...]".

\subsection{GESTÃO DE PESSOAS NA ESFERA PÚBLICA}

Para compreender a forma de trabalho do $\mathrm{RH}$ na esfera pública, faz-se necessário discorrer sobre seus aspectos culturais. Para tal, traz-se a percepção de Carvalho (2014) que, apesar de generalista, reflete as características de parte da administração pública: questões culturais de resistência à mudança; processos morosos; hábito de culpar o Estado ou a Instituição pela falta de eficiência; e estigma de trabalhadores com baixo desempenho. Esses elementos mobilizam o fenômeno da desesperança aprendida, na qual a conformidade predomina e o objetivo implícito é evitar problemas, cumprindo as regras e nada mais, alimentados, particularmente, pela noção de ausência de competição e de luta por sobrevivência no mercado.

Um aspecto particular da administração pública é a postura de seus gestores, os quais sofrem de maneira direta os efeitos das decisões políticas. Os cargos são ocupados em conformidade com a alta gestão, que tende a ser trocada seguindo os períodos eleitorais correspondentes ao seu nível de inserção (municipal, estadual, federal). Assim, os gestores dessa organização tendem a vivenciar seu papel no cargo de modo mais transitório e, ao deixá-lo, o profissional passa a se reportar a um ex-subordinado. Decorre dessa situação o fenômeno denominado "pacto de mediocridade": um acordo implícito de convivência em que os gestores evitam mudar regras, impedem que sejam feitas grandes cobranças ou que se agite o ambiente, com receio de represálias posteriores, quando os cargos podem ser invertidos (SILVA, 2014). Ao mesmo tempo, a troca periódica de gestores, baseada em critérios de afinidade e nem sempre sustentadas em projetos organizacionais, acarretam alterações radicais na condução da organização e/ou no arquivamento de projetos em andamento (ORSI \& SILVA, 2014).

Buscando profissionalizar e modernizar a administração pública, o Plano Diretor de Reforma do Aparelho do Estado, de 1995, propôs uma mudança de cultura de burocrática para gerencial (CRUZ, 2014). Apesar desse esforço, estudos posteriores e o relatório de Avaliação da Gestão de RH no Governo, realizado pela Organização para a Cooperação e 
Desenvolvimento Econômico (OCDE), em 2010, demonstram que diversas características continuam existindo. Teixeira, Salomão e Nascimento (2014) afirmam que persistem situações como: baixa preocupação com a gestão e com o desempenho, sendo o foco o controle do cumprimento de normas; remuneração desvinculada do desempenho e gratificação distorcida; excesso de burocracia que inibe a evolução; inércia gerencial; baixa frequência de concursos, gerando estagnação e limitada motivação para inovação; quadro de cargos rígido, dificultando a mobilidade e causando risco constante de desvio de função; etc.

Dez anos após a proposição do Plano Diretor, buscando novamente meios de modernizar e tornar mais eficaz a gestão pública, o Governo Federal instituiu, em 2005, o Programa Nacional de Gestão Pública e Desburocratização (GESPÚBLICA), encarregado de implantar o Modelo de Excelência em Gestão Pública (MEGP). Este tem como base o

pensamento sistêmico, aprendizado organizacional, cultura da inovação, liderança e constância de propósitos, orientação por processos e informação, visão de futuro, geração de valor, comprometimento com as pessoas, foco no cidadão e na sociedade, desenvolvimento de parcerias, responsabilidade social, controle social e gestão participativa [...] (PEDROSO et al., 2014, p. 110).

Para orientar a utilização das práticas de excelência e avaliar os órgãos, o modelo é composto por oito dimensões/indicadores: Liderança; Estratégias e Planos; Cidadãos; Sociedade; Pessoas; Processos; Resultados; Informações e Conhecimento. A dimensão Pessoas examina sete requisitos: organização do trabalho (autonomia nos diferentes níveis); gestão do desempenho (de pessoas e equipes); identificação de necessidades de capacitação (considerando as estratégias e as necessidades das pessoas); realização de atividades de capacitação; identificação e prevenção de riscos relacionados a saúde, segurança e ergonomia; identificação de fatores que afetam o bem-estar, a satisfação, a motivação e o clima e como são tratados; e o meio de avaliação da satisfação das pessoas (BRASIL, 2009).

Pedroso et al. (2014) realizaram um estudo com o intuito de investigar a percepção dos gestores em relação a aplicação e avaliação do modelo de excelência em gestão nas organizações públicas. Eles fizeram a pesquisa em organizações públicas do Ceará, premiadas em 2010 e 2011 pelo GESPÚBLICA, onde os gestores perceberam que o modelo serve de guia para a definição de estratégias, fornecendo ferramentas de gestão, e 
identificaram ser fundamental o envolvimento da alta direção, para que ocorra uma real mudança cultural. Apesar das premiações e do avanço dessas organizações, certos elementos do modelo burocrático de administração ainda se mostravam presentes, como a rigidez da estrutura hierárquica e a ênfase em normas e controles, e não em processos e serviços. Além disso, as instituições pesquisadas não utilizavam as orientações do modelo no gerenciamento de pessoas, item fundamental da gestão (PEDROSO et al., 2014).

Além da GESPÚBLICA, consoante Camões, Fonseca e Porto (2014), outras políticas foram desenvolvidas pelo Governo Federal para melhorar a gestão do capital humano, tais como: o sistema de gestão do desempenho atrelado à remuneração (Decreto $\mathrm{n}$ ․ 7.133, de 2010); o planejamento da força de trabalho (Decreto $n$ ㅇ 6.944, de 2009); as políticas de saúde do trabalhador (Decreto $n$ o 6.833, de 2009); e a política e as diretrizes para desenvolvimento de pessoal (PNDP). Esta, instituída em 2006, pelo Decreto $n^{\circ} 5.707$, trouxe orientações para o desenvolvimento constante de competências individuais e organizacionais por meio da gestão por competências (GARCIA, 2014, PINTO \& SILVA, 2015).

Embora orientada pelo Decreto $n^{\circ} 5.707$, a gestão por competências na área pública ainda é um tema pouco explorado na literatura brasileira (CAMARGO et al., 2016). Garcia (2014) aponta que, segundo o relatório da OCDE, de 2010, poucos órgãos estão baseando seu sistema de gestão no enfoque proposto pela PNDP, tendo dificuldades com a cultura e com a estrutura legalista da administração pública. Isso porque não basta a capacitação para adquirir conhecimento, é preciso saber utilizá-lo e, principalmente, querer fazê-lo, inserindo na discussão a necessidade de mudança cultural (PINTO \& SILVA -RS, 2015).

Na mesma linha, Siqueira e Nascimento (2016) afirmam que é raro encontrar organizações públicas com estratégias efetivas de treinamento e desenvolvimento de pessoal. Abrucio (2014) aponta que a gestão de desempenho no setor público ainda é muito subjetiva, pois não possui uma métrica definida (conjunto de metas, mecanismos para alcançá-las, monitoramento e avaliação). Outra questão que agrava o mau uso das avaliações é o fato de que os gestores podem ser destituídos de seus cargos a qualquer momento, dessa forma, todos recebem notas altas, independentemente de seu 
comprometimento - fenômeno chamado por alguns autores de cultura de leniência (ORSI \& SILVA, 2014).

Apesar da criação de políticas e decretos, questões essenciais relativas à gestão estratégica de pessoas ainda não fazem parte da realidade da maioria das entidades públicas (VIEIRA et al., 2011). O departamento de pessoal, em muitos casos, fica restrito às atividades rotineiras de admissão, registros, remuneração, férias, entre outras (MATOSO et al., 2016), sendo altamente inspirado no pensamento gerencial clássico (TERABE e BERGUE, 2014). Matoso et al. (2016) apontam que, antes de tentar tornar o RH uma consultoria interna de atuação estratégica, focada em talentos e orientada para a mudança, é preciso garantir que suas atividades rotineiras estejam sendo gerenciadas de forma adequada.

Existe a ilusão de que só é possível fazer gestão com boas práticas no setor privado (SILVA, 2014) e que os temas relacionados a pessoas são de responsabilidade exclusiva da área de RH (TERABE e BERGUE, 2014). Um elemento do ambiente público que contribui para essa realidade é a baixa integração do setor de $\mathrm{RH}$ com a alta administração, dificultando o reconhecimento desse como unidade estratégica e de suporte à modernização (CAMÕES, FONSECA e PORTO, 2014).

Teixeira, Salomão e Nascimento (2014) defendem que as comparações do departamento de RH do setor público com o privado são injustas, imprecisas, idealizadas e com base apenas nos melhores exemplos. Os autores apontam que esse departamento cumpre sua função de apoio, mas não tem poder real para interferir nas decisões da linha de frente das organizações públicas. Segundo eles, o problema maior é a falta de gestão praticada pelos gerentes e chefes de departamento em todos os níveis hierárquicos que, assumindo ou compartilhando algumas funções típicas do RH em suas equipes, como "seleção, treinamento, orientação, salários, demissão" (TEIXEIRA, SALOMÃO \& NASCIMENTO, 2014, p. 54), teriam um impacto maior na obtenção de resultados e superação de problemas.

Segundo Terabe e Bergue (2014, p. 20), a gestão estratégica de pessoas no setor público possui ou necessita dos seguintes elementos:

a) a função de RH próxima à alta administração; 
b) os agentes públicos (servidores e agentes políticos) posicionados no centro da organização;

c) a gestão de pessoas como compromisso de todos os gestores;

d) a adoção de uma perspectiva sistêmica e contextualizada; e

e) o reconhecimento das pessoas como elemento de continuidade da organização (TERABE E BERGUE, 2014, p. 20).

O 'reconhecimento das pessoas como elemento de continuidade da organização' pode ser percebido nos dois cases apresentados a seguir, publicados na página do Top Ser Humano 2016, da Associação Brasileira de Recursos Humanos do Rio Grande do Sul. No Hospital de Clínicas de Porto Alegre, as áreas de gestão de pessoas e de comunicação trabalham em conjunto e buscam valorizar a trajetória de dedicação de seus funcionários com uma homenagem anual de Distinção por tempo de serviço, por entenderem que o sentimento de orgulho e o comprometimento com os princípios da organização são fundamentais para a retenção de talentos (FOLLETTO et al., 2016).

O Tribunal de Contas do Estado do Rio Grande do Sul tem a valorização das pessoas como um dos valores da sua identidade organizacional e já ganhou diversos prêmios ao apresentar seus cases. Um exemplo é o Programa de Preparação do Ingressante, criado para contornar as dificuldades relatadas por gestores e ingressantes nos primeiros meses de trabalho, no qual o $\mathrm{RH}$ combina interesses e características do ingressante com as necessidades da organização (ESGC, 2016).

Outro elemento fundamental para a modernização e para o aumento da qualidade dos processos do serviço público são os sistemas informatizados para a área de RH (PINTO \& SILVA, 2015). A partir de um trabalho de diagnóstico sobre o sistema de informação de gestão de pessoas realizado pelo consultor Noman (2012), junto aos 27 estados da federação, o mesmo constatou que a maioria dos gestores da área de pessoal não está plenamente satisfeita com o sistema que utiliza. Apesar de muitos estados não planejarem trocá-lo, o autor aponta a contratação de um sistema integrado de mercado como a melhor solução. Além de detalhes sobre um programa informatizado, em seu relatório são feitas quatro recomendações que devem ser acatadas: formulação de um projeto de melhorias em gestão de pessoas; grupos de estudos entre organizações diferentes para trocar experiências; união dos estados para realizar compras em conjunto, melhorando a 
negociação; e medição de satisfação de gestores e usuários em relação ao sistema de informação.

Percebe-se que a gestão de pessoas no setor público tem sido tensionada a mudanças. Algumas práticas têm sido propostas como tentativa de se alcançar novos patamares, mas elas ainda são minoria e, por isto, concursos e outras formas de dar visibilidade a elas têm sido bem recebidos, haja vista que, além de ser um reconhecimento àquilo que já está sendo feito, pode servir de motivação e inspiração.

\section{PROCEDIMENTOS METODOLÓGICOS}

Esta pesquisa é do tipo qualitativa e utiliza o método de estudo de caso (YIN, 2001). Para identificar práticas de gestão de pessoas propostas pelos departamentos de $\mathrm{RH}$ de organizações públicas sediadas em Porto Alegre, foram entrevistados servidores e empregados públicos dos setores de gestão de pessoas de cinco organizações, exceto na organização $C$, uma vez que o empregado está em um nível hierárquico acima da área de RH. Essas características estão demonstradas no Quadro 1.

Quadro 1 - Características das organizações

\begin{tabular}{|c|c|c|}
\hline Organização & Poder & No de empregados \\
\hline A & Autônomo & De 500 a 1.000 \\
\hline B & Judiciário & De 1.000 a 1.500 \\
\hline C & Executivo & Menos de 500 \\
\hline D & Judiciário & Mais de 2.000 \\
\hline E & Executivo & De 1.000 a 1.500 \\
\hline
\end{tabular}

Fonte: Elaborado pelos autores, com dados da pesquisa, 2016.

As entrevistas realizadas foram abertas e em profundidade (ROESCH, 2007) e buscaram verificar quais das atividades executadas pelo RH poderiam ser consideradas 'boas práticas'. Por estas, entende-se o conjunto das técnicas, processos, atividades e procedimentos identificados, utilizados, comprovados e reconhecidos por diversas organizações, em determinada área do saber, como sendo os melhores quanto ao mérito, à eficácia e ao sucesso alcançados pela sua aplicação na realização de uma tarefa (Dicionário Infopedia, s/d., s/p.). As entrevistas ocorreram na sede de cada organização e tiveram a 
duração média de uma hora. Apresenta-se no Quadro 2 a relação de entrevistados ${ }^{1}$, identificados por organização pesquisada:

Quadro 2 - Características dos entrevistados

\begin{tabular}{|c|l|l|l|l|l|}
\hline Organização & Sexo & Idade & \multicolumn{1}{|c|}{ Cargo/Função } & $\begin{array}{l}\text { Tempo de } \\
\text { casa }\end{array}$ & Formação \\
\hline A & Feminino & 47 anos & $\begin{array}{l}\text { Supervisora de } \\
\text { Gestão de Pessoas }\end{array}$ & 16 anos & $\begin{array}{l}\text { Ciências econômicas com especialização } \\
\text { em Gestão Estratégica de Pessoas }\end{array}$ \\
\hline B & Feminino & 34 anos & $\begin{array}{l}\text { Psicologia com especialização em } \\
\text { Trabalho }\end{array}$ & $\begin{array}{l}\text { Instituições em Análise e mestrado em } \\
\text { Psicologia Social e Institucional }\end{array}$ \\
\hline B & Masculino & 48 anos & $\begin{array}{l}\text { Técnico judiciário - } \\
\text { núcleo de } \\
\text { capacitação }\end{array}$ & $\begin{array}{l}\text { Publicidade e Propaganda com } \\
\text { especialização em Administração da } \\
\text { Tecnologia da Informação }\end{array}$ \\
\hline C & Masculino & 42 anos & $\begin{array}{l}\text { Coordenador } \\
\text { Administrativo e } \\
\text { Financeiro }\end{array}$ & $\begin{array}{l}\text { Administração com especialização e } \\
\text { mestrado em Administração }\end{array}$ \\
\hline D & Feminino & 45 anos & $\begin{array}{l}\text { Chefe da Seção de } \\
\text { Funções } \\
\text { Comissionadas }\end{array}$ & 23 anos & $\begin{array}{l}\text { Administração com especialização em } \\
\text { Psicologia Organizacional }\end{array}$ \\
\hline E & Feminino & 39 anos & $\begin{array}{l}\text { Consultora interna } \\
\text { de RH }\end{array}$ & 10 anos & $\begin{array}{l}\text { Administração com especialização em } \\
\text { Gestão Estratégica de Pessoas }\end{array}$ \\
\hline E & Feminino & 39 anos & $\begin{array}{l}\text { Consultora interna } \\
\text { de RH }\end{array}$ & 10 anos & $\begin{array}{l}\text { Administração com especialização em } \\
\text { Cargos e Salários }\end{array}$ \\
\hline
\end{tabular}

Fonte: Elaborado pelos autores, com dados da pesquisa, 2016.

As entrevistas foram gravadas, com o consentimento dos entrevistados e, posteriormente, transcritas e analisadas, utilizando-se a análise de conteúdo, que consiste em um conjunto de procedimentos sistemáticos e objetivos de categorização e descrição do conteúdo das mensagens (BARDIN, 1977). Para complementá-la, foram usadas informações do Concurso Inovação no Setor Público (CISP), promovido pela Escola Nacional de Administração Pública, desde 1996, sendo pesquisadas as premiações relacionadas às práticas de gestão de pessoas. Esta análise intencionou identificar as ações de gestão de pessoas nacionalmente valorizadas, considerando os critérios adotados por esta organização, o que indicaria a dimensão de 'boas práticas'.

No transcorrer da verificação das ações em gestão de pessoas descritas pelos entrevistados, constatou-se que as práticas mencionadas estavam alinhadas às principais práticas de gestão de pessoas. As categorias, então, acabaram sendo as frentes essenciais de atuação, como se apresenta na próxima seção.

1 Na organização $B$ foram feitas duas entrevistas individuais com dois empregados, e na organização $E$ foi realizada uma entrevista com a participação de duas empregadas, porém as análises dos resultados na última seção foram feitas por boas práticas por organização. 


\section{ANÁLISE DOS DADOS}

Nesta seção, apresenta-se as formas de atuação apontadas pelas cinco organizações participantes da pesquisa como suas boas práticas. Para facilitar a compreensão, os dados foram sintetizados e organizados em tabelas, uma para cada categoria. Na coluna da esquerda são mencionadas as práticas e à direita, a organização correspondente, com a identificação $A, B, C, D$ ou $E$. Ressalta-se que as empresas pesquisadas podem realizar práticas que não foram mencionadas nas entrevistas. Portanto, o resultado se refere a ações julgadas relevantes pelos entrevistados, mas não são, necessariamente, todas. As oito categorias encontradas, apontadas em ordem alfabética, são: acompanhamento; avaliação ou gestão do desempenho; capacitação ou treinamento; cargos e salários; desenvolvimento de lideranças; estrutura do $\mathrm{RH}$; programas; e planejamento de pessoal.

\subsection{ACOMPANHAMENTO}

A categoria acompanhamento diz respeito a uma proposta institucional de aproximação aos empregados, buscando a qualificação da relação entre o trabalhador e a organização. Nas palavras do entrevistado B, acompanhamento consiste em "um espaço de escuta e assessoramento".

Quadro 3 - Ações de Acompanhamento

\begin{tabular}{|c|c|}
\hline Ações & Org \\
\hline Assessoria ao gestor para auxiliar no trato de dificuldades com um empregado ou com a equipe. & A \\
\hline $\begin{array}{l}\text { Trabalho pontual com funcionários com baixo rendimento (verificação de necessidade de treinamento } \\
\text { técnico ou acompanhamento psicológico). }\end{array}$ & A \\
\hline Acompanhamento aos ingressantes quando se identifica que podem ter dificuldades. & A \\
\hline $\begin{array}{l}\text { Programa de mentoria nos seis primeiros meses de trabalho, com seis reuniões de acompanhamento com } \\
\text { e sem a chefia do setor. }\end{array}$ & A \\
\hline Núcleo específico para acompanhamento de servidores e gestores desde que ingressam na organização. & $\mathrm{B}$ \\
\hline $\begin{array}{l}\text { Acompanhamento sistemático ao longo do estágio probatório, focado na inserção do servidor no trabalho } \\
\text { e na equipe. Recentemente as chefias foram incluídas. }\end{array}$ & B \\
\hline $\begin{array}{l}\text { Visitas periódicas de acompanhamento com as principais chefias da área fim para falar da gestão de } \\
\text { pessoas na equipe. }\end{array}$ & B \\
\hline $\begin{array}{l}\text { Acompanhamento de servidores deficientes para compatibilizar as atividades através de ajustes no local } \\
\text { de trabalho e inserção na equipe durante o estágio probatório. }\end{array}$ & B \\
\hline Psicóloga terceirizada faz acompanhamento eventual com servidores em situações problemáticas. & $\mathrm{C}$ \\
\hline Psicóloga terceirizada faz estudos e já provocou a saída de um gestor assediador. & $\mathrm{C}$ \\
\hline Há uma seção de acompanhamento funcional que atua em situações problemáticas. & $\mathrm{D}$ \\
\hline $\begin{array}{l}\text { Psicólogas terceirizadas atendem pontualmente: equipes com conflitos, novos empregados, } \\
\text { acompanhamento psicológico periódico em setores operacionais, situações pessoais, entrevista de } \\
\text { desligamento, apoio aos gestores e equipe. }\end{array}$ & $\mathrm{E}$ \\
\hline Psicólogas terceirizadas fazem o acompanhamento de novos empregados no período de experiência & $\mathrm{E}$ \\
\hline
\end{tabular}

Fonte: Elaborado pelos autores, com dados da pesquisa, 2016. 
Pelos relatos dos entrevistados, percebe-se que há um cuidado com a relação empresa/empregado/gestor em todas as organizações, porém, algumas atuam de forma mais sistêmica e padronizada. Um dos entrevistados transmitiu sua forma de encarar essa atividade: "nosso objetivo é cuidar do trabalho, porque quando tu cuida do trabalho tu cuida das pessoas, tu tá cuidando também da organização, porque não tem um trabalho bem feito se as pessoas não são bem cuidadas, se essas chefias não são olhadas também, se elas não recebem um suporte para o trabalho delas" (Entrevistado B), corroborando Silva (2014) sobre a importância de conhecer e envolver o colaborador no trabalho.

Uma das consequências percebidas do trabalho de acompanhamento, segundo o entrevistado B, é a amenização da cultura de descartabilidade de pessoas, praticada, colocando-se à disposição do RH as pessoas que não possuem o desempenho desejado uma ação considerada comum no setor público em virtude da estabilidade dos servidores e de sua permanência na organização. O acompanhamento permite a identificação de dificuldades em estágio inicial e a intervenção sobre elas. Esta mudança ocorre devido ao trabalho de aproximação com os líderes e à sensibilização quanto ao seu papel de gestor de pessoas, aspecto apontado por Terrabe e Bergue (2014) como necessário à gestão estratégica.

Duas das cinco organizações possuem um programa de acompanhamento sistemático de ingressantes durante um período definido, sendo que uma delas utiliza a mentoria. Esses exemplos consistem em práticas relevantes para objetivos estratégicos. Segundo Rocha (2014), a mentoria, no contexto empresarial, tem por finalidade intensificar o compartilhamento de conhecimentos e sabedoria mediante uma relação estruturada entre um profissional mais e um menos experiente, agregando valor à organização como um todo.

\subsection{AVALIAÇÃO / GESTÃO DO DESEMPENHO}

A segunda categoria considera práticas relacionadas à avaliação e à gestão do desempenho, é uma ferramenta estratégica de gestão por competências, que consta no Decreto $\mathrm{n}^{\circ}$ 5.707, de 2006, que trata das diretrizes para o desenvolvimento de pessoal. A gestão do desempenho, consoante Garcia (2014), permite preencher as lacunas entre as competências individuais e aquelas necessárias para atingir as metas da organização. 
Quadro 4 - Ações na categoria Avaliação / Gestão de desempenho

\begin{tabular}{|l|c|}
\hline \multicolumn{1}{|c|}{ Ações } & Org \\
\hline \begin{tabular}{l} 
Nota positiva na avaliação é um dos requisitos para promoção por mérito. \\
\hline $\begin{array}{l}\text { Ciclo anual com fase intermediária de acompanhamento individual obrigatório formalizado no sistema } \\
\text { (aberto para registros durante todo o ciclo). }\end{array}$
\end{tabular} & A e C \\
\hline $\begin{array}{l}\text { Registro negativo é pré-requisito para solicitar a saída do funcionário do setor. } \\
\text { Feito pela chefia e o funcionário manifesta ou não a concordância (a pontuação que vale para fins de } \\
\text { progressão é a da chefia). }\end{array}$ & A \\
\hline Avaliação anual de aspectos comportamentais e técnicos, até um tempo de casa determinado. & B e C \\
\hline $\begin{array}{l}\text { Espaço para avaliar a chefia, os recursos e condições oferecidas para o desenvolvimento do trabalho. } \\
\text { Auto avaliação (servidor elenca e pontua as suas atividades) para conversar sobre as notas com a } \\
\text { chefia. }\end{array}$ & B \\
\hline $\begin{array}{l}\text { Servidor e chefia devem elaborar juntos um plano de desenvolvimento para ajudar o servidor a superar } \\
\text { os déficits. }\end{array}$ & B \\
\hline $\begin{array}{l}\text { Sistema informatizado de avaliação de desempenho no qual cada servidor cadastra seu plano de } \\
\text { trabalho anual com alguns objetivos que são avaliados por comitê externo na elaboração e na } \\
\text { conclusão do plano. }\end{array}$ & C \\
\hline Sistema online. Ciclo relacionado a entrada do servidor no órgão. & D \\
\hline \begin{tabular}{l} 
Avaliação anual independente do tempo de casa e da possibilidade de progressão. \\
\hline Chefia avalia o servidor e é gerado um Plano de Desenvolvimento Individual.
\end{tabular} & D e E \\
\hline
\end{tabular}

Fonte: Elaborado pelos autores, com dados da pesquisa, 2016.

Todas as organizações participantes da pesquisa utilizam a ferramenta de Avaliação de Desempenho de forma online, cada uma com suas particularidades, conforme se nota nas descrições do Quadro 4. Um ponto comum é que nessas instituições a avaliação é feita pela chefia imediata, não havendo outros avaliadores, o que reflete a descentralização da gestão de pessoas, que antes ficava toda a cargo dos profissionais do departamento de $\mathrm{RH}$. Com a perspectiva estratégica, os gestores diretos assumem a responsabilidade do acompanhamento, da gestão e da avaliação de desempenho porque são aqueles que, efetivamente, estão mais próximos dos servidores.

Em duas organizações, foi citado o Plano de Desenvolvimento Individual como consequência da avaliação, comprovando que a ferramenta não está sendo utilizada apenas para subsidiar uma promoção, mas, também para desenvolver o empregado. De acordo com os entrevistados, as cinco organizações procuram utilizar o ciclo completo de gerenciamento do desempenho, não se restringindo ao evento da avaliação, o que está relacionado com a primeira categoria: acompanhamento. Contudo, alguns entrevistados apontaram a resistência de certos gestores diretos para assumir atividades de gestão de pessoas, remetendo-as ao $\mathrm{RH}$. Em parte, isto se deve à cultura estabelecida e às consequências de algumas fragilidades nas competências desses gestores, as quais estão relacionadas, principalmente, às práticas de feedback. 
O entrevistado $C$ explicou como funciona o sistema de gestão do desempenho praticado em sua organização, que se diferencia bastante dos demais. O ponto central é a criação e a manutenção de um plano de trabalho anual por empregado, analisado por uma comissão, no qual o funcionário deve propor melhorias em sua própria função, tendo como base sua experiência na organização e sua formação acadêmica. $O$ fato de o plano, que subsidia a maior parte da avaliação, ser elaborado pelo próprio empregado promove engajamento e oferece parâmetros mais claros sobre os pontos de melhoria e metas individuais, tornando a gestão de desempenho uma ferramenta mais objetiva, já que os passos a seguir são estabelecidos.

Em consonância com os autores Almeida, Silva e Gaspar (2014) e com Silva, Perret e Pardini (2015), o entrevistado A afirma que a vinculação da avaliação à progressão funcional impede que seja um instrumento de desenvolvimento efetivo. Como resultado, o entrevistado B constata que ocorre um "festival de dez [nas avaliações] para não prejudicar o colega". Todavia, em duas organizações o resultado da avaliação não está diretamente relacionado à progressão, pois há outros requisitos, como a realização de capacitações, por exemplo, apresentado na seção 4.3.

\subsection{CAPACITAÇÃO}

A terceira categoria é referente à capacitação, ou seja, a forma como o RH encara e organiza as atividades de treinamento, desenvolvimento e educação oferecidas.

Quadro 5 - Ações da Categoria Capacitação

\begin{tabular}{|l|c|}
\hline \multicolumn{1}{|c|}{ Ações } & Org \\
\hline Competências mapeadas para cada cargo. & $\mathrm{A}$ \\
\hline $\begin{array}{l}\text { Possui uma escola responsável pelos treinamentos, vinculada à presidência. Área técnica auxilia nas } \\
\text { demandas técnicas e RH nas gerenciais e comportamentais. }\end{array}$ & $\mathrm{A}$ \\
\hline Plano de capacitação bianual. & $\mathrm{A}$ \\
\hline Alguns cursos EaD (ensino a distância). & $\mathrm{A}$ \\
\hline Geralmente utiliza os instrutores internos. & $\mathrm{A}, \mathrm{B}, \mathrm{E}$ \\
\hline $\begin{array}{l}\text { Boa rede de contatos externa - muitos palestrantes não cobram. } \\
\text { Incentivo aos instrutores: pontuação para promoção. }\end{array}$ & $\mathrm{A}$ \\
\hline $\begin{array}{l}\text { Banco de instrutores internos: servidores cadastram perfil e áreas de interesse - bem qualificados e com } \\
\text { atuação acadêmica. }\end{array}$ & $\mathrm{A}$ \\
\hline \begin{tabular}{l} 
Incentivo aos instrutores: retribuição financeira por hora aula e produção de conteúdo. \\
\hline Orientação aos instrutores internos é geralmente feita por consultora externa especialista.
\end{tabular} & $\mathrm{B}, \mathrm{D}, \mathrm{E}$ \\
\hline $\begin{array}{l}\text { Foca em oficinas em que as pessoas participem e interajam ativamente em grupos de estudos ou casos } \\
\text { de discussão, evitando capacitações unicamente expositivas. }\end{array}$ & $\mathrm{B}$ \\
\hline $\begin{array}{l}\text { Cada área fim possui uma trilha de aprendizagem organizada em módulos desenhados a partir do } \\
\text { mapeamento de competências técnicas e comportamentais. }\end{array}$ & $\mathrm{B}$ \\
\hline
\end{tabular}




\begin{tabular}{|l|c|}
\hline \multicolumn{1}{|c|}{ Ações } & Org \\
\hline Parceria com outras regionais para troca de cursos desenvolvidos internamente. & B \\
\hline Só oferece um curso ao compreender a necessidade da área interessada (credibilidade). & B \\
\hline $\begin{array}{l}\text { Não é realizado Levantamento de necessidades de treinamento, pois as necessidades da área fim estão } \\
\text { mapeadas e organizadas nas trilhas de aprendizagem. Para área meio o levantamento é realizado junto } \\
\text { aos gestores. }\end{array}$ & B \\
\hline $\begin{array}{l}\text { Adicional de qualificação: percentual sobre o salário base vinculado a horas de capacitação em um } \\
\text { período definido. }\end{array}$ & B e D \\
\hline $\begin{array}{l}\text { Auxílio para especialização: após concluir o curso o servidor concorre ao ressarcimento de até 60\% } \\
\text { através de edital. }\end{array}$ & B \\
\hline Contratam muitas capacitações externas e fazem parcerias com instituições de ensino. & C e D \\
\hline Há incentivo a multiplicação de conhecimentos, mas não há treinamento para instrutores. & C \\
\hline Capacitação voltada para a prática do trabalho. & D \\
\hline $\begin{array}{l}\text { Levantamento de necessidades de treinamento: o gestor conversa com o servidor e informa as } \\
\text { necessidades de treinamento na própria avaliação de desempenho. }\end{array}$ & D e E \\
\hline $\begin{array}{l}\text { A seção de capacitação é responsável por analisar as necessidades, buscar e proporcionar os } \\
\text { treinamentos. }\end{array}$ & D \\
\hline $\begin{array}{l}\text { Bastante capacitação voltada a motivação. } \\
\text { Matriz de capacitação atrelada ao plano de cargos. }\end{array}$ & D \\
\hline $\begin{array}{l}\text { Sem recursos financeiros, o setor de capacitação organiza cursos internos e divulga muitos cursos EaD } \\
\text { (ensino a distância). }\end{array}$ & E \\
\hline
\end{tabular}

Fonte: Elaborado pelos autores, com dados da pesquisa, 2016.

Um ponto comum em relação à capacitação, citado por todos os entrevistados, é a utilização de instrutores internos, ratificando uma tendência e uma forma de compartilhar conhecimentos. Segundo Travi et al. (2016, p.18), o programa que utiliza instrutores internos "cria um sentimento de valorização profissional, de pertencimento, fazendo da instrutoria uma oportunidade de imprimir mudanças significativas na cultura da empresa". Além disso, os treinamentos online ( $\mathrm{EaD})$ também foram mencionados pela maioria dos entrevistados como um jeito de contornar restrições financeiras e abranger um maior número de servidores.

O entrevistado B informou que a área de capacitação conta com o assessoramento de consultoras externas de renome, uma em educação corporativa e outra em EaD, de modo que todos os treinamentos são elaborados com atenção ao protagonismo do aluno, a metodologias pedagógicas para adultos e à aplicabilidade no trabalho. O RH desta organização possui uma relação próxima com os setores da área fim, e juntos, periodicamente, analisam o alinhamento entre as trilhas de aprendizagem e suas necessidades atuais de treinamento, garantindo uma atuação mais efetiva da área de capacitação. Apesar de não referirem tantos detalhes quanto ao cuidado com as atividades de capacitação, os entrevistados $A$ e $D$ indicaram que as instituições oferecem diversos treinamentos voltados para a prática do trabalho, grande parte organizada internamente. 
Os treinamentos abarcam questões técnicas e comportamentais nas cinco organizações. Todavia, o entrevistado B enfatizou que a cultura da organização não é favorável a capacitações exclusivamente comportamentais, sendo esta abordada como uma consequência das interações de grupo em treinamentos técnicos. Já as outras organizações realizam capacitações nesta linha, como comentou o entrevistado E: "Eu vejo mais a capacitação em termos comportamentais, técnico a gente aprende, todo mundo tem condições: uma leitura, uma troca de conhecimento com o colega sabe, mas a questão comportamental ela é muito mais complicada".

Referentemente ao modelo de gestão por competências, regulamentado pelo Decreto no 5.707, de 2006, os entrevistados A e B citaram diretamente a sua utilização, e o entrevistado E informou que a empresa não o utiliza. Segundo Silva e Mello (2011), a maioria das organizações utiliza a gestão de competências apenas sob a perspectiva individual, ou seja, focando no desenvolvimento de conhecimentos, habilidades e atitudes dos empregados. Esta gestão é vista como uma atividade da área de $\mathrm{RH}$, sem articulação com a estratégia organizacional e com pouca atenção às competências organizacionais. Percebe-se que os dados colhidos nas entrevistas estão alinhados com a revisão de literatura, já que ambos demonstram que poucas organizações públicas possuem estratégias efetivas de gestão por competências.

\subsection{CARGOS E SALÁRIOS}

A quarta categoria retrata práticas relacionadas a cargos e salários, mais especificamente sobre critérios de promoção e progressão na carreira, adicionais e gratificações.

Quadro 6 - Ações da categoria Cargos e salários

\begin{tabular}{|l|c|}
\hline \multicolumn{1}{|c|}{ Ações } & Org \\
\hline $\begin{array}{l}\text { Promoções intercaladas: um ano por antiguidade, outro por mérito. } \\
\text { Promoção por mérito: avaliação de desempenho e pontuação mínima de } 40 \text { pontos entre: horas de } \\
\text { treinamento interno e externo, atividades extras (mentoria, comissões, brigadista, instrutoria, etc.), } \\
\text { graduação e pós-graduação. }\end{array}$ & A \\
\hline $\begin{array}{l}\text { Progressão vinculada a data de ingresso na organização e a nota igual ou superior a sete na avaliação de } \\
\text { desempenho. }\end{array}$ & B \\
\hline $\begin{array}{l}\text { Após completar todas as promoções horizontais de um nível, é preciso ter } 80 \text { horas de capacitação no } \\
\text { período para subir um nível - a progressão dura até 12 anos. }\end{array}$ & B \\
\hline $\begin{array}{l}\text { Adicional fixo de graduação (empregados de nível médio), pós-graduação, mestrado e doutorado: } \\
\text { percentual em cima do salário-base. }\end{array}$ & B e D \\
\hline \begin{tabular}{l} 
Pós-Graduações antecipam a progressão nos níveis - a progressão dura até 15 anos. \\
\hline
\end{tabular} & C \\
\hline
\end{tabular}




\begin{tabular}{|l|c|}
\hline \multicolumn{1}{|c|}{ Ações } & Org \\
\hline $\begin{array}{l}\text { A remuneração é dividida em vencimento básico, titulação e gratificação. A gratificação é dividida em } \\
\text { institucional (40\%) e individual (60\% - metas e comportamental), este último atrelado ao Plano de } \\
\text { Trabalho Individual. }\end{array}$ & C \\
\hline $\begin{array}{l}\text { Para promoção é necessária nota igual ou superior a 8 na avaliação de desempenho. } \\
\text { Plano de cargos e salários baseado em maturidade, classificado em quatro fatores: formação, experiência } \\
\text { externa, conhecimento da organização e treinamento. Cada fator é pontuado e atualizado anualmente e } \\
\text { as pontuações mais altas de mérito, maturidade e antiguidade têm progressão salarial. }{ }^{2}\end{array}$ & E \\
\hline
\end{tabular}

Fonte: Elaborado pelos autores, com dados da pesquisa, 2016.

Como mencionado na seção 4.2, a avaliação é um dos únicos ou o único requisito para promoção/progressão na carreira, sendo que apenas as organizações A e E citaram a antiguidade ou o tempo de casa também como premissa para a promoção. Este dado demonstra que a maioria das organizações participantes da pesquisa não adota o critério antiguidade, revelando uma gestão de carreiras mais moderna, focada no desempenho. Porém, conforme encontrado na literatura e mencionado nas entrevistas, os resultados da avaliação de desempenho, atrelados à progressão salarial, muitas vezes não refletem a realidade.

Talvez, como forma de minimizar esta distorção, algumas organizações ainda possuem critérios de capacitação como requisitos complementares à avaliação de desempenho. No que tange à graduação e à pós-graduação, há diferentes procedimentos: algumas organizações as consideram para progressão e outras para um adicional ao salário base. A organização $C$ possui um formato específico de composição do salário, demonstrando uma atenção à meritocracia, na qual é preciso desempenhar bem para receber a recompensa, além de atrelar ao desempenho da organização.

\subsection{DESENVOLVIMENTO DE LIDERANÇAS}

A quinta categoria demonstra a atuação das organizações em relação ao desenvolvimento de lideranças, que tem programas quem buscam capacitar os gestores, os quais, tradicionalmente, posicionavam-se como 'chefes'. O foco é incentivá-los na disposição ativa, no engajamento e na potencialização do desempenho de seus subordinados, atuando como parceiros de negócio na obtenção de resultados e na superação de problemas, uma postura raramente adotada pelos gestores públicos, segundo Teixeira, Salomão e Nascimento (2014).

2 O Departamento de Coordenação e Governança das Empresas Estatais aprovou o plano apenas para enquadrar os salários e não para a progressão. 
Quadro 7 - Ações da categoria Desenvolvimento de lideranças

\begin{tabular}{|l|l|}
\hline Ações & Org \\
\hline $\begin{array}{l}\text { Programa de desenvolvimento de lideranças focado no líder desenvolvedor e no incentivo a prática do } \\
\text { feedback. Inicialmente feito por contratação, atualmente estruturado com as psicólogas. }\end{array}$ & A \\
\hline $\begin{array}{l}\text { Programa de desenvolvimento de lideranças focado na dimensão comportamental realizado a cada } \\
\text { dois anos com consultores externos capacitados e experientes. }\end{array}$ & B \\
\hline Gestores devem passar por 30 horas de capacitação no período de dois anos. & B e D \\
\hline Curso de liderança e motivação ministrado por psicóloga terceirizada. & C \\
\hline $\begin{array}{l}\text { Encontro anual de gestores com palestras e treinamentos práticos durante 2,5 dias com palestrantes e e } \\
\text { instituiçães externas de renome (em 2016 foi realizado em EaD por falta de recursos financeiros). }\end{array}$ & D \\
\hline Treinamentos pontuais de desenvolvimento gerencial ministrados por instituição externa. & E \\
\hline
\end{tabular}

Fonte: Elaborado pelos autores, com dados da pesquisa, 2016.

Segundo Silva e Mello (2011), a atividade de liderança se tornou altamente complexa, exigindo um novo perfil estratégico do gestor de pessoas, para o qual a competência sobrepõe-se à qualificação. Os autores afirmam que, por trás de estratégias organizacionais bem-sucedidas, estão líderes que mobilizam pessoas e transferem conhecimentos, visando o funcionamento eficaz e harmônico das equipes e que, para isto, a perspectiva comportamental ou social é uma das competências requeridas. Corroborando a literatura, a totalidade dos entrevistados citou que as capacitações envolvem, necessariamente, questões comportamentais.

Referentemente aos temas motivação e engajamento, o entrevistado $D$ informou que "esses temas fazem parte dos treinamentos, principalmente dos gestores, porque na verdade é pra estimulá-los a estimular o seu grupo de trabalho". Na mesma linha, o entrevistado B afirmou que "gestão de pessoas se faz é lá no setor de trabalho, não é palestra de $\mathrm{RH}^{\text {", }}$ corroborando Terrabe e Bergue (2014), os quais destacaram que a gestão de pessoas deve ser um compromisso de todos os gestores.

As organizações $A, B$ e $D$ possuem programas periódicos de desenvolvimento de lideranças e em duas destas está normatizada a carga horária de treinamento obrigatório para todos os gestores. Não foi mencionado durante as entrevistas o acompanhamento que a área de gestão de pessoas faz especificamente desses programas de desenvolvimento, porém, analisando-se a categoria 1 (acompanhamento), percebe-se que as mesmas três organizações realizam ações de assessoria aos gestores em temas de gestão de pessoas. A realização dos treinamentos não garante a correta aplicação dos conhecimentos, já que é preciso saber utilizá-lo e querer fazê-lo (ESGC, 2016). Contudo, a existência dessas ofertas de atividades para o desenvolvimento de líderes como processos permanentes é uma iniciativa positiva. 


\subsection{ESTRUTURA DO RH}

A sexta categoria não traz uma prática específica de gestão de pessoas, mas demonstra como está organizada a estrutura do setor de RH das organizações pesquisadas.

Quadro 8 - Ações da categoria Estrutura do RH

\begin{tabular}{|l|c|}
\hline \multicolumn{1}{|c|}{ Ações } & Org \\
\hline $\begin{array}{l}\text { Todas as ferramentas de apoio aos projetos são desenvolvidas pela área de informática. } \\
\text { Reestruturação recente do organograma de RH, agrupando todas as áreas sob duas supervisões de modo } \\
\text { a facilitar a gestão e a comunicação. }\end{array}$ & A \\
\hline $\begin{array}{l}\text { Cada programa possui uma coordenação e são realizadas reuniões gerenciais mensais para acompanhar o } \\
\text { cumprimento das metas. }\end{array}$ & A \\
\hline $\begin{array}{l}\text { O RH é dividido em setores: Gestão de Pessoas, Saúde e Administração de Pessoal. O setor de GP é } \\
\text { dividido em núcleos: ergonomia, capacitação e gestão de pessoas. Há um alinhamento entre os } \\
\text { diferentes núcleos do setor de GP, que realizam algumas atividades em conjunto. }\end{array}$ & B \\
\hline Sistema de cadastro funcional é informatizado com todos os registros, inclusive de treinamento. & C \\
\hline Sistema integrado de RH. & D \\
\hline Gerência de RH dividida em setores: pessoal, treinamentos, segurança e medicina do trabalho. & E \\
\hline $\begin{array}{l}\text { Duas consultoras internas de RH responsáveis pelo alinhamento estratégico das atividades. } \\
\text { Fonte: Elaborado pelos autores, com dados da pesquisa, 2016. }\end{array}$ & $\mathrm{E}$ \\
\hline
\end{tabular}

A estrutura do $\mathrm{RH}$ varia entre as organizações, uma vez que depende de seu tamanho e da organização interna. Como práticas interessantes, pode-se citar os casos das organizações A e E: na primeira, além dos setores de $\mathrm{RH}$, cada programa desenvolvido pela área possui uma coordenação e tem acompanhamento mensal; e, na segunda, adicionalmente aos setores, a gerência conta com consultoras que atuam com uma perspectiva sistêmica, buscando alinhar permanentemente cada atividade dos setores com o planejamento estratégico.

Ao explicar sobre a forma de organização da área, a maioria dos entrevistados citou seu sistema informatizado, corroborando com o entendimento de Pinto e Silva (2015), que delinearam ser este um elemento fundamental para a qualidade dos processos. 0 entrevistado $B$ disse que o núcleo de capacitação possui um banco de dados antigo, mas funcional, que gera relatórios consistentes, permitindo o controle e o planejamento das atividades de treinamento.

\subsection{PROGRAMAS}

A sétima categoria apresenta as práticas relacionadas a programas desenvolvidos pelo RH nas áreas de integração, motivação, reconhecimento, qualidade de vida, etc. 
Quadro 9 - Ações da Categoria Programas

\begin{tabular}{|l|c|}
\hline \multicolumn{1}{|c|}{ Ações } & Org \\
\hline $\begin{array}{l}\text { Programa ininterrupto de preparação para aposentadoria. Foco: refletir sobre o momento de vida, } \\
\text { minimizar angústias e medos. }\end{array}$ & $\mathrm{A}$ \\
\hline $\begin{array}{l}\text { Diversos programas com ações preventivas e programas permanentes de qualidade de vida: } \\
\text { Fiscalização da saúde e postura, Ginástica laboral, Grupo de corrida, Acompanhamento para gestantes. }\end{array}$ & $\mathrm{A}$ \\
\hline Programas de integração com atividades lúdicas. & $\mathrm{A}$ \\
\hline Programas gratuitos para a sociedade. & $\mathrm{A}$ \\
\hline Homenagem com medalhas para valorização do tempo de serviço. & $\mathrm{A}$ \\
\hline Programas da área de saúde, como campanha de emagrecimento, campanha de redução do estresse. & $\mathrm{B}$ \\
\hline Oficina de teatro. & $\mathrm{D}$ \\
\hline Cursos/oficinas pontuais voltados a qualidade de vida. & $\mathrm{D}$ e E \\
\hline $\begin{array}{l}\text { Programa de preparação para aposentadoria (não permanente). } \\
\text { Projeto em fase inicial de resgate de servidores desestimulados ou em final de carreira para estimular } \\
\text { ou buscar a troca de setor. }\end{array}$ & $\mathrm{D}$ \\
\hline Centro de bem-estar com academia e espaço de lazer. & $\mathrm{D}$ \\
\hline Programa de acompanhamento para gestantes em parceria com clínica de psicologia. & $\mathrm{E}$ \\
\hline
\end{tabular}

Fonte: Elaborado pelos autores, com dados da pesquisa, 2016.

A segurança no trabalho é influenciada, entre outros aspectos, pela percepção de suporte organizacional, ou seja, é a crença que o empregado tem de que a organização cuida do seu bem-estar e dá valor a suas contribuições (Souza et al., 2015). O entrevistado A mencionou um grande número de programas e atividades organizados pelo $\mathrm{RH}$ com o objetivo de integrar e motivar o corpo funcional. Nesta organização, como apresentado na seção 4.6, cada programa possui uma equipe responsável dentro do RH. Os demais entrevistados indicaram ações pontuais realizadas pela gestão de pessoas, algumas em parceria com a área da saúde. $O$ entrevistado $C$ não fez nenhuma menção desse tipo de prática.

Percebe-se, especialmente nas organizações $A$ e $D$, uma intenção de engajar o corpo funcional e reconhecer sua importância mediante atividades que vão além do trabalho em si, já que, conforme Silva (2014), o sentimento de realmente fazer parte da empresa torna as pessoas mais produtivas. Ressalta-se que a existência desses programas por si só não garante o bem-estar ou a motivação, é preciso que eles façam parte de um plano de gestão que englobe condições apropriadas de trabalho, suporte da chefia, comunicação precisa, etc., pois "uma boa prática de gestão leva ao engajamento, à eliminação de injustiças e faz as pessoas se sentirem respeitadas" (TEIXEIRA, SALOMÃO \& NASCIMENTO, 2014, p. 68).

\subsection{PLANEJAMENTO DE PESSOAL}

As atividades de recrutamento e seleção são realizadas por meio de concurso público, que seleciona unicamente pelos conhecimentos teóricos: prova objetiva, redação e 
prova de títulos, os quais enquadram o profissional em um cargo específico. Apesar de não ter sido mencionado nas entrevistas, o concurso precisa ter um alinhamento estratégico e, segundo Silva e Mello (2011), algumas organizações públicas estão utilizando um desenho de cargos multifuncionais, permitindo maior mobilidade, e inserindo o item "competências requeridas", demonstrando desde o edital um planejamento mais estratégico da sua força de trabalho. A oitava e última categoria se refere ao planejamento de pessoal, especificamente quanto às práticas de ingresso, alocação e relotação.

Quadro 10 - Ações da categoria Planejamento de pessoal

\begin{tabular}{|c|c|}
\hline Ações & Org \\
\hline $\begin{array}{l}\text { Entrevista de ingresso com pesquisa comportamental para verificar qualificação, bagagem acadêmica e } \\
\text { profissional e alocar a pessoa na organização conforme as suas competências. }\end{array}$ & A \\
\hline $\begin{array}{l}\text { Curso de formação de ingresso com participação dos gestores que buscam "vender seu setor" aos } \\
\text { ingressantes. }\end{array}$ & A \\
\hline $\begin{array}{l}\text { Programa de movimentação e seleção interna. RH disponibiliza as vagas através de edital e os } \\
\text { interessados devem atualizar seu perfil no Banco de Talentos e preencher um formulário de motivação. } \\
\text { O processo é sigiloso. }\end{array}$ & A \\
\hline $\begin{array}{l}\text { Entrevista de ingresso para conciliar o perfil com o que a administração define como prioritário no } \\
\text { momento. }\end{array}$ & B \\
\hline $\begin{array}{l}\text { Situações mais complicadas de movimentação passam pelo } \mathrm{RH} \text {, que busca compreender o motivo, } \\
\text { auxiliar o servidor a encontrar uma vaga compatível com o seu perfil e expectativas e fazer um } \\
\text { acompanhamento com o servidor. }\end{array}$ & B \\
\hline $\begin{array}{l}\text { Está buscando normatizar critérios para trocar servidores de setor: feedback do gestor antes do } \\
\text { desligamento e manter a pessoa até encontrar outro setor. }\end{array}$ & B \\
\hline $\begin{array}{l}\text { Programa de integração: uma semana na matriz e duas para conhecer todas as áreas e processos } \\
\text { técnicos e administrativos da regional antes de ser lotado em um setor. }\end{array}$ & $\mathrm{C}$ \\
\hline Possui seção específica que cuida do ingresso e remoção de servidores. & $\mathrm{D}$ \\
\hline $\begin{array}{l}\text { Programa de cinco dias de integração para novos servidores da área fim, com treinamento técnico e } \\
\text { algumas orientações do RH. }\end{array}$ & $\mathrm{D}$ \\
\hline $\begin{array}{l}\text { Psicólogas terceirizadas atendem novos empregados: entrevista inicial e integração, e atuam em casos } \\
\text { de readaptação/reintegração. }\end{array}$ & $\mathrm{E}$ \\
\hline
\end{tabular}

Fonte: Elaborado pelos autores, com dados da pesquisa, 2016.

As organizações $A, C$ e D possuem programas estruturados de integração de novos empregados. Na organização $\mathrm{C}$, por exemplo, as três primeiras semanas de trabalho são utilizadas para apresentar ao ingressante todas as áreas e atividades, proporcionando um entendimento da organização como um todo. Em relação à movimentação interna, nas organizações B e D, ela geralmente é feita diretamente pelo networking (ou "rádio corredor", conforme aponta o entrevistado D), e o RH é comunicado apenas para a oficialização. Diferentemente, na organização $A$, há um programa estruturado e transparente de movimentação que permite oportunidades iguais a todos. Os demais entrevistados não mencionaram este assunto. 
O entrevistado A citou uma série de programas relacionados ao ingresso, alocação e relotação de servidores, como por exemplo, ao final do curso de formação do ingressante, o $\mathrm{RH}$ seleciona até três candidatos com perfil mais adequado a cada cargo e encaminha para entrevista com o gestor. Observa-se, na atuação da organização A, o princípio "reconhecimento das pessoas como elemento de continuidade da organização", citado por Terabe e Bergue (2014) como necessário à gestão estratégica de pessoas.

O entrevistado $D$ citou que, no ingresso, as vagas na área fim são sempre prioridade, mesmo que o novo servidor possua um ótimo currículo para uma área meio. $A$ mesma organização possui um banco de talentos para os servidores atualizarem seu perfil e a área de interesse, para os setores buscarem candidatos para suas vagas, todavia, a ferramenta não é utilizada. Com isso, pode-se inferir que alguns talentos são desperdiçados, deixando de agregar valor para a organização e aumentando o risco de desmotivação do servidor.

\subsubsection{Iniciativas em Gestão de pessoas premiadas no CISP}

Para ampliar o campo de análise das práticas de gestão de pessoas que aproximam a uma atuação estratégica, expõe-se, nesta seção, casos apontados como bem-sucedidos pelo Concurso Inovação no Setor Público (CISP), promovido pela Escola Nacional de Administração Pública. Das dezenove edições do CISP, de 1996 até 2016 (ENAP, 2016), dezesseis iniciativas em gestão de pessoas foram premiadas, as quais estão resumidas no Quadro 11 e classificadas conforme as categorias apresentadas.

Quadro 11 - Iniciativas em gestão de pessoas premiadas no CISP

\begin{tabular}{|c|c|c|c|c|c|}
\hline Prática premiada & Organização & Edição & Lugar & Categoria & Descrição \\
\hline $\begin{array}{c}\text { Sistema de avaliação de } \\
\text { desempenho individual }\end{array}$ & Inmetro & 14 & 6 & $\begin{array}{c}\text { Gestão de } \\
\text { desempenho }\end{array}$ & $\begin{array}{c}\text { Pactuação anual de um plano de } \\
\text { trabalho individual vinculado aos } \\
\text { objetivos organizacionais }\end{array}$ \\
\hline $\begin{array}{c}\text { Programa de Reabilitação } \\
\text { Profissional }\end{array}$ & $\begin{array}{c}\text { Hospital de } \\
\text { Clínicas de } \\
\text { Porto Alegre }\end{array}$ & 10 & 10 & $\begin{array}{c}\text { Planejamento } \\
\text { de pessoal }\end{array}$ & $\begin{array}{c}\text { Reinserir trabalhadores afastados } \\
\text { por doença, respeitando suas } \\
\text { necessidades e demandas da } \\
\text { instituição }\end{array}$ \\
\hline Pool de capacitação & $\begin{array}{c}\text { Presidência da } \\
\text { República }\end{array}$ & 9 & 7 & Capacitação & $\begin{array}{c}\text { Gestão por competências, } \\
\text { desconcentração do processo de } \\
\text { capacitação e constituição de } \\
\text { parcerias }\end{array}$ \\
\hline $\begin{array}{c}\text { Programa de valorização } \\
\text { ALGO+ }\end{array}$ & $\begin{array}{c}\text { Instituto } \\
\text { Nacional do } \\
\text { Câncer }\end{array}$ & 7 & - & Programas & $\begin{array}{c}\text { Identificar empregados de } \\
\text { destaque, buscando estimular a } \\
\text { dedicação e a competência }\end{array}$ \\
\hline
\end{tabular}




\begin{tabular}{|c|c|c|c|c|c|}
\hline Prática premiada & Organização & Edição & Lugar & Categoria & Descrição \\
\hline $\begin{array}{l}\text { Sistema de treinamento } \\
\text { por cotas por unidade }\end{array}$ & $\begin{array}{l}\text { Instituto } \\
\text { Nacional do } \\
\text { Câncer }\end{array}$ & 6 & 16 & Capacitação & $\begin{array}{l}\text { Otimizar a distribuição de verba e } \\
\text { atingir mais profissionais do nível } \\
\text { estratégico ao operacional }\end{array}$ \\
\hline $\begin{array}{l}\text { Avaliação dos Postos de } \\
\text { Trabalho e Remuneração } \\
\text { por Competências }\end{array}$ & $\begin{array}{l}\text { Secretaria de } \\
\text { Gestão do } \\
\text { Ministério do } \\
\text { Planejamento } \\
\end{array}$ & 6 & 1 & $\begin{array}{l}\text { Cargos e } \\
\text { salários }\end{array}$ & $\begin{array}{l}\text { Premiar o desempenho técnico e } \\
\text { reter servidores capacitados }\end{array}$ \\
\hline $\begin{array}{l}\text { Sistema de gestão do } \\
\text { conhecimento e alocação } \\
\text { de novos servidores }\end{array}$ & $\begin{array}{c}\text { Banco Central } \\
\text { do Brasil }\end{array}$ & 6 & 5 & $\begin{array}{c}\text { Planejamento } \\
\text { de pessoal }\end{array}$ & \begin{tabular}{|c|} 
Adequação do perfil \\
comportamental e de \\
conhecimentos do futuro servidor \\
aos postos de trabalho
\end{tabular} \\
\hline $\begin{array}{c}\text { Programa de Readaptação } \\
\text { ao Trabalho }\end{array}$ & $\begin{array}{c}\text { Caixa } \\
\text { Econômica } \\
\text { Federal }\end{array}$ & 5 & 10 & $\begin{array}{c}\text { Planejamento } \\
\text { de pessoal }\end{array}$ & \begin{tabular}{|c|} 
Suporte aos gerentes, e \\
$\begin{array}{c}\text { acompanhamento aos empregados } \\
\text { afastados para readaptação }\end{array}$ \\
\end{tabular} \\
\hline Reestruturação do RH & $\begin{array}{l}\text { Universidade } \\
\text { Federal de SC }\end{array}$ & 5 & 15 & $\begin{array}{l}\text { Estrutura do } \\
\qquad \mathrm{RH}\end{array}$ & $\begin{array}{l}\text { Transformação da estrutura do } \\
\text { Departamento de RH em flexível, } \\
\text { horizontal e por processos }\end{array}$ \\
\hline Banco de Oportunidades & $\begin{array}{c}\text { Caixa } \\
\text { Econômica } \\
\text { Federal }\end{array}$ & 4 & 9 & $\begin{array}{l}\text { Desenvolvi- } \\
\text { mento de } \\
\text { lideranças }\end{array}$ & $\begin{array}{l}\text { Sistema dinâmico e permanente de } \\
\text { identificação e desenvolvimento de } \\
\text { possíveis gestores }\end{array}$ \\
\hline $\begin{array}{l}\text { Sistema de Gestão de } \\
\text { Desempenho }\end{array}$ & \begin{tabular}{|c|}
$\begin{array}{c}\text { Delegacia da } \\
\text { Receita Federal } \\
\text { de Belém }\end{array}$ \\
\end{tabular} & 3 & - & $\begin{array}{c}\text { Gestão de } \\
\text { desempenho }\end{array}$ & - \\
\hline $\begin{array}{l}\text { Plano integrado de } \\
\text { capacitação }\end{array}$ & $\begin{array}{l}\text { Universidade } \\
\text { Federal de } \\
\text { Uberlândia } \\
\end{array}$ & 1 & - & Capacitação & $\begin{array}{c}\text { Desenvolvimento pessoal e } \\
\text { profissional, feedback positivo das } \\
\text { chefias }\end{array}$ \\
\hline $\begin{array}{l}\text { Política de avaliação e } \\
\text { premiação }\end{array}$ & EMBRAPA & 1 & - & $\begin{array}{c}\text { Gestão de } \\
\text { desempenho }\end{array}$ & $\begin{array}{c}\text { Negociação de metas por unidade } \\
\text { e avaliação de desempenho } \\
\text { semestral com premiação }\end{array}$ \\
\hline $\begin{array}{l}\text { Núcleo de Psicologia e } \\
\text { Assistência Social }\end{array}$ & $\begin{array}{c}\text { Polícia Federal } \\
\text { do RS }\end{array}$ & 1 & - & $\begin{array}{l}\text { Acompanha- } \\
\text { mento }\end{array}$ & $\begin{array}{c}\text { Promover o bem-estar e prevenir } \\
\text { problemas ligados a natureza } \\
\text { estressante do trabalho }\end{array}$ \\
\hline $\begin{array}{l}\text { Avaliação em estágio } \\
\text { probatório }\end{array}$ & $\begin{array}{l}\text { Universidade } \\
\text { Federal do } \\
\text { Paraná }\end{array}$ & 1 & - & $\begin{array}{c}\text { Gestão de } \\
\text { desempenho }\end{array}$ & $\begin{array}{c}\text { Auxiliar na adaptação ao trabalho, } \\
\text { feedback às chefias }\end{array}$ \\
\hline
\end{tabular}

Fonte: Elaborado pelos autores, com dados da pesquisa, 2016.

As informações obtidas com a análise das premiações em gestão de pessoas revelam que, desde 1996, as organizações públicas vêm modernizando suas práticas e estão indo além das atividades do RH tradicional, em um movimento que busca se opor à afirmação de Vieira et al. (2011) que afirma que a maioria das entidades públicas não encara a gestão de pessoas de forma estratégica.

As categorias mais premiadas foram a avaliação de desempenho, a capacitação e o planejamento de pessoal, demonstrando uma preocupação com o acompanhamento do desenvolvimento dos servidores, com a meritocracia e com a adequada ambientação de servidores novos ou que retornaram do afastamento. Dessa forma, confirma-se que os subsistemas de RH devem englobar práticas que reconheçam e valorizem os servidores, já 
que satisfação, motivação e desenvolvimento profissional e pessoal do corpo funcional são requisitos para o seu desempenho, que é um requisito para o desempenho da administração pública (PINTO \& SILVA, 2015).

\subsubsection{Visão geral de categorias de boas práticas adotadas pelas organizações pesquisadas e pelas premiadas no CISP}

No Quadro 12, apresenta-se o quantitativo de práticas adotadas por organização e por categoria.

Quadro 12 - Visão geral de categorias de boas práticas

\begin{tabular}{|c|c|c|c|c|c|c|c|}
\hline \multirow[t]{2}{*}{ Categoria } & \multirow{2}{*}{$\begin{array}{c}\text { CISP - } \mathbf{N}^{\circ} \\
\text { organizações }\end{array}$} & \multicolumn{5}{|c|}{$\begin{array}{l}\mathbf{N}^{\circ} \text { de práticas } \\
\text { por organização }\end{array}$} & \multirow[t]{2}{*}{$\begin{array}{l}\text { Total de } \\
\text { práticas }\end{array}$} \\
\hline & & $A$ & $\mathrm{~B}$ & $\mathrm{C}$ & $\mathrm{D}$ & $\mathrm{E}$ & \\
\hline Acompanhamento & 1 & 3 & 3 & 2 & 1 & 2 & 12 \\
\hline Avaliação/gestão de desempenho & 4 & 4 & 4 & 2 & 3 & 1 & 18 \\
\hline Capacitação/treinamento & 3 & 7 & 11 & 2 & 7 & 5 & 35 \\
\hline Cargos e salários & 1 & 2 & 3 & 2 & 2 & 1 & 11 \\
\hline Desenvolvimento de lideranças & 1 & 1 & 2 & 1 & 2 & 1 & 8 \\
\hline Estrutura do $\mathrm{RH}$ & 1 & 3 & 1 & 1 & 1 & 2 & 9 \\
\hline Programas: reconhecimento, motivação & 1 & 5 & 1 & 0 & 4 & 3 & 14 \\
\hline Plan. de pessoal: ingresso, aloc, relotaç. & 3 & 4 & 5 & 1 & 2 & 1 & 16 \\
\hline
\end{tabular}

Fonte: Elaborado pelos autores, 2017.

As iniciativas mais adotadas e valorizadas estão na área de capacitação, talvez por influência do Decreto $n^{\circ}$ 5.707, de 2006, que incentiva a educação. Especialmente em algumas organizações, ficou claro o cuidado do RH em promover a capacitação de fato, o desenvolvimento, e não apenas o treinamento operacional. Em segundo e terceiro lugares, com uma frequência menor, foram citadas ou premiadas práticas de avaliação ou gestão do desempenho, também regulamentada por decreto, e práticas relacionadas ao planejamento de pessoal (ingresso, alocação e relotação de servidores).

Conforme apresentado na revisão de literatura, para ser estratégica, a gestão de pessoas deve ser um compromisso de todos os gestores, permitindo um impacto maior na conquista de resultados e na resolução de problemas. Porém, o desenvolvimento de lideranças foi a prática menos apontada, o que mostra que a dimensão Liderança, do Modelo de Excelência em Gestão Pública, parece não ser um dos focos da atuação da área de $\mathrm{RH}$. 
Como consideração final desta análise, são trazidos dois temas relevantes à gestão estratégica de pessoas que não receberam suficientes destaques ou menções nas entrevistas para serem categorizados: gestão do clima e alinhamento da gestão de pessoas com a alta gestão. Das cinco organizações, apenas duas (A e D) utilizam a ferramenta de Pesquisa de Clima Organizacional, sendo que em apenas uma esta é sistemática e feita pela área de GP. O entrevistado C citou a proximidade entre a coordenação e o corpo funcional como fator influenciador do clima e do engajamento, no entanto, não falou se há um gerenciamento concreto desses fatores. A organização B, apesar de não utilizar a pesquisa, possui uma área de acompanhamento, responsável pelo diagnóstico e por sugerir ações preventivas e corretivas.

Pode-se considerar que não há um investimento sistematizado em diagnosticar o nível de (in)satisfação dos trabalhadores, pelo menos não com esta ferramenta. A ausência de informação a este respeito pode impactar no envolvimento dos trabalhadores, o que, de acordo com Mota e Cordeiro (2015), é fundamental para alcançar as metas organizacionais. Desta forma, amplia-se a dificuldade do setor público em apresentar melhores resultados e satisfazer as necessidades da sociedade.

$\mathrm{O}$ alinhamento ou a proximidade do $\mathrm{RH}$ com a alta gestão e com o planejamento estratégico, pontuado por Terabe e Bergue (2014) como fundamental para a consolidação da gestão estratégica de pessoas no setor público, ainda não ocorre nas organizações pesquisadas, pelo menos não de modo expressivo. Foi detectada apenas uma prática no CISP ligada a esse tema, pela qual a Radiobrás foi premiada por seu sistema de gestão participativa. Nas organizações entrevistadas, com exceção da A, as menções foram pontuais e superficiais, podendo-se inferir que, mesmo existindo, não têm tanta relevância, corroborando as análises de Camões, Fonseca e Porto (2014). Neste caso, a adoção de boas práticas de $\mathrm{RH}$ tende a ser menos efetiva, já que o fato de haver objetivos da área de $\mathrm{RH}$ descritos no planejamento estratégico não significa que o trabalho desse setor seja estratégico e esteja alinhado com os demais objetivos da empresa.

\section{CONCLUSÃO}

Esta pesquisa analisou tendências de gestão de pessoas no setor público e, mediante uma amostra de organizações pesquisadas, pôde-se perceber que o RH delas não é restrito 
às atividades básicas do departamento de pessoal, bem como as áreas de RH das organizações com iniciativas premiadas no CISP.

Agrupando as iniciativas das organizações premiadas no CISP às boas práticas informadas pelas organizações participantes da pesquisa, foi possível responder à pergunta central deste estudo: quais práticas vêm sendo adotadas nos departamentos de recursos humanos de organizações públicas em termos de gestão de pessoas? As práticas adotadas, segundo a amostra, são relacionadas ao acompanhamento, avaliação/gestão de desempenho, capacitação/treinamento, cargos e salários, desenvolvimento de lideranças, estrutura do $\mathrm{RH}$, programas de $\mathrm{RH}$ e planejamento de pessoal (ingresso, alocação e relotação), sendo as mais adotadas na área de capacitação.

Este estudo contribui com a área de gestão de pessoas, especialmente do setor público, à medida que mostra e analisa diversas iniciativas empreendidas por diferentes organizações. As informações obtidas demonstram ser possível desenvolver atividades mais estratégicas de $\mathrm{RH}$, mesmo com restrições financeiras e culturais, com interferências políticas, com a rotatividade de gestores, sem haver a possibilidade de demissão e tantas outras particularidades do setor.

Foi possível perceber, no discurso dos entrevistados, a genuína intenção de tornar o $\mathrm{RH}$ cada vez mais estratégico, ao mesmo tempo que apontaram questões culturais como barreiras que impedem ou dificultam uma real transformação não só do papel do setor, mas da gestão pública como um todo, corroborando os autores pesquisados. Cabe considerar a possibilidade de que $\mathrm{o}$ RH de algumas organizações públicas adote boas práticas simplesmente por imposição superior ou legal, ou tenha o intuito de se modernizar, mas não tenha a visão sistêmica ou a integração necessária com a alta gestão. Contudo, sabe-se que a modernização é um processo e que o setor de RH de muitas empresas privadas também passa por isso.

Como limitação deste estudo, aponta-se a perspectiva adotada, já que foram entrevistadas apenas pessoas do setor de recursos humanos ou, no caso da organização $C$, da alta administração. Os empregados ou servidores dessas organizações, alvos das ações de $\mathrm{RH}$, podem ter uma percepção diferente das atividades e das intenções dos entrevistados. Para estudos futuros, sugere-se uma pesquisa focada em apenas uma organização que tenha 
sucesso na adoção de práticas modernas de gestão de pessoas, para mostrar detalhadamente como as práticas foram iniciadas, de que forma são conduzidas e o que é necessário em termos de estrutura e cultura empresarial para a boa condução da gestão de pessoas. Além disso, recomenda-se que sejam realizadas entrevistas com funcionários da organização escolhida, para analisar o que acontece na prática e não apenas o que é relatado pelo $\mathrm{RH}$. Por fim, propõe-se um estudo com uma amostra ampliada, de modo a validar ou contrapor o que foi apresentado nesta pesquisa.

\section{REFERÊNCIAS}

ABRUCIO, F. Uma leitura da gestão de pessoas sob a perspectiva do mérito, desempenho e resultados. In: TEIXEIRA, H. J.; BASSOTTI, I. M.; SANTOS T. S. Mérito, desempenho e resultados: ensaios sobre gestão de pessoas para o setor público. 1. ed. São Paulo: FIA/USP, 2014. Cap. 1, p. 23-40.

ALMEIDA, G.; SILVA, N. A.; GASPAR, S. R. Um olhar sobre os órgãos de recursos humanos do governo do estado de São Paulo. In: TEIXEIRA, H. J.; BASSOTTI, I. M.; SANTOS T. S. Mérito, desempenho e resultados: ensaios sobre gestão de pessoas para o setor público. 1. ed. São Paulo: FIA/USP, 2014. Cap. 3, p. 73-98.

ARAUJO, H. M. C. C. Impacto do I Ciclo de Capacitação em Gestão Participativa do Instituto Chico Mendes de Conservação da Biodiversidade. Cadernos ENAP, Brasília, v. 37, n. 3, p. 5989, 2014.

BARDIN, L. Análise de Conteúdo. Lisboa: Edições 70, 1977.

BRASIL. Ministério do Planejamento, Orçamento e Gestão. Secretaria de Gestão. Programa Nacional de Gestão Pública e Desburocratização - GesPública; Instrumento para Avaliação da Gestão Pública - 250 e 500 Pontos; Brasília; MP, SEGES 2009 Versão 1/2009.

BRASIL. Decreto n. 5.707, de 23 de fev. de 2006. Institui a Política e as Diretrizes para o Desenvolvimento de Pessoal da administração pública federal direta, autárquica e fundacional, e regulamenta dispositivos da Lei n. 8.112, de 11 de dezembro de 1990. Disponível em < http://www.planalto.gov.br/ccivil_03/_Ato20042006/2006/Decreto/D5707.htm>. Acesso em: 10 nov. 2016.

CAMARGO, E. J. B; PEREIRA, A. S.; GRZYBOVSKY, D.; LORENZON, A. L. H. Gestão de Pessoas na Administração Pública Federal: Análise dos Modelos Adotados no Período 1995 a 2010. Revista interdisciplinar de gestão social, Bahia, v. 5, n. 1, p. 63-87, jan./abr. 2016.

CAMÕES, M. R. S.; FONSECA, D. R.; PORTO, V. Estudos em Gestão de Pessoas no Serviço Público. Cadernos ENAP, Brasília, v. 37, Apresentação, p. 6-11, 2014. 
CARVALHO, H. C. Serviço Público: o cemitério da motivação? In: TEIXEIRA, H. J.; BASSOTTI, I. M.; SANTOS T. S. Mérito, desempenho e resultados: ensaios sobre gestão de pessoas para o setor público. 1. ed. São Paulo: FIA/USP, 2014. Cap. 5, p. 129-152.

CRUZ, M. C. M. T. A prática e os embates das avaliações de desempenho em municípios paulistas. In: TEIXEIRA, H. J.; BASSOTTI, I. M.; SANTOS T. S. Mérito, desempenho e resultados: ensaios sobre gestão de pessoas para o setor público. 1. ed. São Paulo: FIA/USP, 2014. Cap. 8, p. 235-256.

Dicionário Infopédia da Língua Portuguesa. Porto: Porto Editora, 2003-2017. Disponível em: <https://www.infopedia.pt/dicionarios/lingua-portuguesa/boas-práticas> Acesso em: 27 de novembro de 2016.

DONIDA, K. R.; OLIVEIRA; P. W. S. Educação Corporativa e Ensino a Distância: um Estudo no Tribunal Regional Eleitoral do Rio Grande do Norte - TRE/RN. Revista da FAE, Curitiba, v.15, n.1, p. 184-199, jan/jun 2012.

ENAP - Escola Nacional de Administração Pública. Concurso Inovação no Setor Público. Disponível em: <https://inovacao.enap.gov.br>. Acesso em: 27 de novembro de 2016.

ESGC - Escola Superior de Gestão e Controle Francisco Juruena. Integra RH: programa de preparação do ingressante. Top Ser Humano ABRH. Porto Alegre: 2016. Disponível em: <http://www.abrhrs.org.br/sites/default/files/artigos/integrarh_-_top_ser_humano__2016.pdf>. Acesso em: 10 nov. 2016.

FIORENSE, L.; MARTINEZ, M. Influência da cultura e clima organizacional na qualidade de vida no trabalho: revisão da literatura. Revista Destaques Acadêmicos, Lajeado, v. 8, n. 1, p. 100-113, 2016.

FOLLETTO, A. P. L.; BARTHS, C. C.; SCHAFER, C.; PRATES, C. S.; FERRARETTO, E. K.; PEREREIRA, G. M.; CRIPPA, L. H.; SCREMIN, Q. Distinção por tempo de serviço: valorização e reconhecimento aos funcionários do HCPA. Top Ser Humano ABRH. Porto Alegre: 2016. Disponível em:

<http://www.abrhrs.org.br/sites/default/files/artigos/case_hospital_de_clinicas_de_porto_ alegre.pdf >. Acesso em: 10 nov. 2016.

GARCIA, L. B. B. Competências Transversais e Percepção de Suporte à Aprendizagem na SBQ/ANP - Agência Nacional do Petróleo. Cadernos ENAP, Brasília, v. 37, n. 2, p. 39-58, 2014.

MATOSO, J. O.; CORAIOLA, D. M.; ROGLIO, K. D. D. Gestão de recursos humanos na administração pública: um estudo de caso no Governo Estadual de Mato Grosso. Revista Gestão \& Regionalidade, São Caetano do Sul, vol. 32, n. 95, p. 34-51, maio-ago 2016.

MOTA, M. F.; CORDEIRO, J. P. Práticas de Gestão de Recursos Humanos: estudo de caso no setor segurador. European Journal of Applied Business Management, Setúbal, vol. 1, n. 1, p. 93-114, 2015. 
NOMAN, O. Sistema de Gestão de Pessoas. Produto 3. Relatório Final - apoio à preparação de um Programa Nacional de Fortalecimento do Planejamento e Gestão Pública nos Estados Brasileiros. Brasília: ATN/FG-12612-BR, 2012.

ORSI, A.; SILVA, C. M. Gestão do Desempenho no setor público: dificuldades e alternativas de solução. In: TEIXEIRA, H. J.; BASSOTTI, I. M.; SANTOS T. S. Mérito, desempenho e resultados: ensaios sobre gestão de pessoas para o setor público. 1. ed. São Paulo: FIA/USP, 2014. Cap. 7, p. 193-234.

PARANAÍBA, N. F. Satisfação no trabalho e intenção de rotatividade de servidores das carreiras de uma autarquia federal. Cadernos ENAP, Brasília, v. 37, n. 5, p. 117-142, 2014.

PEDROSO, M. N. M. et al. Modelo de excelência em gestão: percepção dos gestores de organizações públicas do estado do Ceará. Revista Gestão Pública Práticas e Desafios, Pernambuco, v. 5, n. 1, p. 107-126, abril 2014.

PINTO, M. C. F.; SILVA, F. M. Gestão de Pessoas na Administração Pública Brasileira: uma análise sobre sua evolução histórica e o atual contexto em transformação. Revista Eletrônica do TCE-RS, Porto Alegre, v. 1, n. 2, p.1-16, julho 2015.

ROCHA, A. F. S. Gestão do conhecimento: processo de implantação do Programa Mentor Petrobras na UO-SEAL. 2014. 111 p. Dissertação. Mestrado em Administração. Universidade Federal da Bahia, Salvador, 2014.

ROESCH, S. M. A. Projetos de estágio e de pesquisa em administração: guia prático para estágios, trabalhos de conclusão, dissertações e estudos de caso. 3 Ed. São Paulo: Atlas, 2007.

SILVA, C. M.; PERRET, N.; PARDINI, A. Implantação de sistema de gestão de pessoas por competências com foco em desenvolvimento profissional no Ministério Público de Santa Catarina. In: Congresso CONSAD de Gestão Pública, VIII, 26, 27 e 28 de maio de 2015, Centro de Convenções Ulysses Guimarães. Brasília: 2015. P. 1-34.

SILVA, F.M.; MELLO, S.P.T. A noção de competência na gestão de pessoas: reflexões acerca do setor público. Revista do Serviço Público, Brasília, v.62, n.2, p. 167-183, abr.-jun. 2011.

SILVA, M. C. S. Pressões culturais e comportamentais na gestão de pessoas no setor público. In: TEIXEIRA, H. J.; BASSOTTI, I. M.; SANTOS T. S. Mérito, desempenho e resultados: ensaios sobre gestão de pessoas para o setor público. 1. ed. São Paulo: FIA/USP, 2014. Cap. 6, p. 153192.

SIQUEIRA, W. M.; NASCIMENTO, D. C. Gestão por competências: desafios encontrados por uma instituição pública de Petrolina durante o processo de implementação. Id on Line Revista Multidisciplinar e de Psicologia, Jaboatão dos Guararapes, v. 10, n. 31, p. 43-62, outubro 2016.

SOUZA, W. S.; SIQUEIRA, M. M. M.; MARTINS, M. Ca. F. Análise da Interdependência do capital psicológico, percepções de suporte e bem-estar no trabalho. Revista Administração em Diálogo, Vol.17, n.2, Mai/Jun/Jul/Ago 2015, p.151-184. 
TEIXEIRA, H. J.; SALOMÃO, S. M.; NASCIMENTO, F. O mesmismo e outros ismos na gestão de pessoas no setor público. In: TEIXEIRA, H. J.; BASSOTTI, I. M.; SANTOS T. S. Mérito, desempenho e resultados: ensaios sobre gestão de pessoas para o setor público. 1. ed. São Paulo: FIA/USP, 2014. Cap. 2, p. 41-71.

TERABE, C. P. A. R.; BERGUE, S. T. Gestão Estratégica de Pessoas como Política Pública: Estudo de Caso no Ministério da Ciência, Tecnologia e Inovação (P12 A X). Cadernos ENAP, Brasília, v. 37, n. 1, p. 11-37, 2014.

TRAVI, B.; SPEROTTO, E. A. F.; BICA, F. R.; VIEIRA, H. S.; KAISER, M.; BELLONI, M. I. B.; GOMES, R. O. Programa de Instrutoria Interna do Banrisul. Top Ser Humano ABRH. Porto Alegre: 2016. Disponível em:

<http://www.abrhrs.org.br/sites/default/files/artigos/case_programa_de_instrutoria_intern a_banrisul_abrh_2016.pdf >. Acesso em: 10 de novembro de 2016.

VIEIRA, C. B.; BOAS, A. A. V.; ANDRADE, R. O. B.; OLIVEIRA, E. R. Motivação na Administração Pública: considerações teóricas sobre a aplicabilidade dos pressupostos das teorias motivacionais na esfera pública. Revista ADMpg Gestão Estratégica, Ponta Grossa, v. 4, n. 1, p. 1-18, 2011.

YIN, R. K. Estudo de caso: planejamento e métodos. 2. Ed. Porto Alegre: Bookman, 2001. 